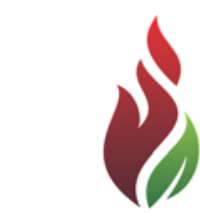

SUSTENERE

Publishing Corporation

\section{SISTEMA JURÍDICO BRASILEIRO DE LICENCIAMENTO AMBIENTAL}

\section{RESUMO}

O licenciamento ambiental no Brasil é o principal instrumento preventivo da Política Nacional do Meio Ambiente e visa o controle da implantação e da operação de empreendimentos ou atividades potencialmente ou efetivamente poluentes com vistas à efetivação do princípio do desenvolvimento sustentável. Tal instrumento cabe aos órgãos executores do SISNAMA, fundamentado em avaliações de impacto ambiental, cujo principal instrumento é o EIA/RIMA e a principal regulação é efetivada pela Lei 6.938/1981, Decreto 99.274/1990, Resoluções do CONAMA, destacando-se a Resolução 237/1997 e a recente Lei Complementar 140/2011. O presente trabalho apresenta o panorama deste sistema de licenciamento ambiental no Brasil considerando-se a recente regulamentação da competência comum ambiental do artigo 23 da CF.

PALAVRAS-CHAVES: Licenciamento Ambiental; SISNAMA; Estudo de Impacto Ambiental; Lei Complementar 140/2011.

\section{BRAZILIAN LEGAL SYSTEM OF ENVIRONMENTAL LICENSING}

\section{ABSTRACT}

The environmental licensing in Brazil is the main preventive instrument of the National Environment Policy and aims at the control of the implantation and the operation of potentially or effectively pollutants undertaking or activities with sights to the accomplishment of the principle of the sustainable development. Such instrument is applied by enforcement agencies of the SISNAMA, based on environmental impact evaluation, whose main instrument is the EIA/RIMA and the main federal statutes is accomplished by Law 6,938/1981. Act 99,274/1990, regulations of the CONAMA, being distinguished the 237/1997 and recent Complementary Law 140/2011. This paper presents an overview of this environmental licensing system in Brazil considering the recent rule of the environmental common competence of article 23 of the Brazilian Constitution.

KEYWORDS: Environmental Licensing; SISNAMA; Environmental Impact Evaluation; Complementary Law 140/2011
Revista Ibero-Americana de

Ciências Ambientais, Aquidabã, v.6, n.2, Jun, Jul, Ago, Set, Out, Nov 2015.

ISSN 2179-6858

SECTION: Articles

TOPIC: Legislação Ambiental

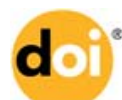

DOI: 10.6008/SPC2179-6858.2015.002.0001

Sandro Luiz da Costa

Universidade Federal de Sergipe, Brasil http://lattes.cnpq.br/7416946586434951 sandrolcosta@infonet.com.br

Maria José Nascimento Soares Universidade Federal de Sergipe, Brasil http://lattes.cnpq.br/8392706159125796 marjonaso@ufs.br

Flávia Moreira Guimarães Pessoa Universidade Federal de Sergipe, Brasil http://lattes.cnpq.br/2987779178843187 flaviampessoa@gmail.com

Received: 19/04/2015

Approved: 14/10/2015 Reviewed anonymously in the process of blind peer

Referencing this:

COSTA, S. L.; SOARES, M. J. G.; PESSOA, F. M. G.. Sistema jurídico brasileiro de licenciamento ambiental. Revista Ibero-Americana de Ciências Ambientais, Aquidabã, v.6, n.2, p.7-22, 2015. DOI: http://dx.doi.org/10.6008/SPC2179$\underline{6858.2015 .002 .0008}$ 


\section{INTRODUÇÃO}

Embora a política ambiental de controle de poluição no Brasil remonte aos anos sessenta do século passado, somente a partir de 1980/1981 o poder público passou a controlar a implantação de empreendimentos potencialmente causadores de poluição ambiental, utilizando-se conjuntamente de instrumentos preventivos como o licenciamento ambiental e a avaliação de impacto ambiental, destacando-se nesta última categoria o estudo prévio de impacto ambiental e seu respectivo relatório (EIA/RIMA). Para a consecução dessa política foi criado o Sistema Nacional do Meio Ambiente (SINAMA), sendo integrado por órgãos em diversos níveis federativos, que, dentro da competência executiva comum para a defesa do meio ambiente, deveria constituir a principal rede pública de atuação para a proteção do meio ambiente e repressão administrativa às infrações ambientais.

No entanto, até dezembro de 2011, antes do advento da Lei Complementar (LC) 140/2011 que regulamentou esta competência comum ambiental dos entes federativos, tal distribuição de atribuições na área do licenciamento ambiental era regulamentada por uma resolução do CONAMA, sendo eivada de inconstitucionalidade, o que colocava em discussão a segurança jurídica dos licenciamentos efetivados e, principalmente, a diretriz de licenciamento em um único órgão ambiental licenciador. Assim, o presente trabalho apresenta o histórico, conceitos, estrutura, competências, fases e sanções do sistema jurídico-ambiental brasileiro de licenciamento ambiental, incluindo o instrumento precursor deste controle público - o estudo de impacto ambiental, tudo isso de acordo com a LC 140/2011.

\section{METODOLOGIA}

Para tanto será necessária uma abordagem sistêmica, valendo-se da interdisciplinaridade que articule saberes do direito e das ciências ambientais, convergentes para um modelo de sustentabilidade ambiental.

\section{DISCUSSÃO TEÓRICA}

Com a publicação em 1962 da Obra Silent Spring de Rachel Carson, discutindo os efeitos deletérios do uso de pesticidas (principalmente o DDT) nos Estados Unidos, iniciou-se uma pressão ao Governo Americano que implicou na criação, em 1969, da Política Ambiental Americana (Nacional Environment Policy Act - NEPA) e, em 1970, da primeira agência ambiental no Mundo, a USEPA (United States Environment Protection Agency), que por sua vez, passou a controlar a implantação de empreendimentos potencialmente poluidores, inclusive exigindo-se estudos de impacto ambiental para subsidiar a aprovação destes empreendimentos. 
Em 1972, foi realizada a Convenção de Estocolmo, sendo criado pela ONU o Programa das Nações Unidas para o Meio Ambiente (PNUMA) e, posteriormente, em 1983, a Comissão Mundial do Meio Ambiente e Desenvolvimento (CMMAD), tendo como relatora Gro Harlem Brundtland. Esta comissão publicou, em 1987, o Relatório Nosso Futuro Comum, onde, além da avaliação da situação do meio ambiente no planeta, conceituou o Desenvolvimento Sustentável como a capacidade das gerações presente satisfazerem suas necessidades sem prejuízo das gerações futuras satisfazerem suas próprias necessidades.

Conforme aponta Costa (2011), em 1988, de forma oportuna, foi promulgada a Constituição Federal Brasileira, incorporando o princípio do desenvolvimento sustentável em seu texto tanto no capítulo atinente ao meio ambiente (art. 225), como na regulação da ordem econômica (art. 172):

Art. 225. Todos têm direito ao meio ambiente ecologicamente equilibrado, bem de uso comum do povo e essencial à sadia qualidade de vida, impondo-se ao Poder Público e à coletividade o dever de defendê-lo e preservá-lo para as presentes e futuras gerações.

Art. 170. A ordem econômica, fundada na valorização do trabalho humano e na livre iniciativa, tem por fim assegurar a todos existência digna, conforme os ditames da justiça social, observados os seguintes princípios: [...] VI - defesa do meio ambiente, inclusive mediante tratamento diferenciado conforme o impacto ambiental dos produtos e serviços e de seus processos de elaboração e prestação.

No referido artigo 225, da CF, verifica-se a obrigatoriedade do poder público e da sociedade de prevenir danos ao meio ambiente (princípio da prevenção). No Brasil, um dos mais importantes instrumentos do poder público para controle preventivo de danos ao meio ambiente por atividades econômicas é o licenciamento ambiental, onde, para atividades que possam causar significativo impacto ambiental, a própria Constituição Federal em seu art. $225, \S^{\circ}$, IV, exige o estudo de impacto ambiental e seu relatório do meio ambiente (EIA/RIMA) como pré-requisito para tal licenciamento.

Seguindo o padrão do EUA, começaram a ser implantados órgãos e agências ambientais no Brasil a partir dos anos setenta do século passado, citando-se aqui a criação da Secretaria Especial do Meio Ambiente (SEMA) em 1973 e o Instituto Brasileiro do Meio Ambiente e dos Recursos Naturais Renováveis (IBAMA) em 1989. Em Sergipe, no ano de 1978, foi criada a Administração Estadual do Meio Ambiente (ADEMA).

No entanto, como ressaltado por Silva (2009, p. 56), o controle da poluição no Brasil tem, mesmo que fragmentário do ponto de vista legislativo e político, suas raízes normativas no Decreto-Lei 303/1967 (criaria o Conselho Nacional de Controle da Poluição), substituído, antes de sua efetivação, pela Lei 5.318/1967 (Instituiu a Política Nacional de Saneamento). No entanto, tais normas não chegaram a ser concretizadas.

A Lei $6.803 / 1980$, que trata das diretrizes básicas para o zoneamento industrial nas áreas críticas de poluição, introduziu no Direito brasileiro o licenciamento ambiental estadual para empreendimentos industriais e o EIA/RIMA. A Política Nacional do Meio Ambiente foi estabelecida 
no Brasil em 1981 pela Lei 6.938, tendo como instrumentos, entre outros, o licenciamento ambiental e as avaliações de impacto ambiental (gênero do qual faz parte o EIA/RIMA, o PRAD, além de outros estudos ambientais) e criando o Sistema Nacional do Meio Ambiente (SISNAMA), formado por órgãos e entidades de todas as esferas federativas (União, Distrito Federal, estados e municípios), cuja função, em suma, é cumprir a obrigação do poder público de defender e preservar o meio ambiente para as 'presentes e futuras gerações' (arts. 23 e 225, da Constituição Federal).

\section{Sistema Nacional do Meio Ambiente}

O SISNAMA tem como principais componentes de sua estrutura em âmbito federal os seguintes órgãos: superior: Conselho de Governo; central: Ministério do Meio Ambiente; consultivo e deliberativo: Conselho Nacional do Meio Ambiente (CONAMA) e; executor: Instituto Brasileiro do Meio Ambiente e dos Recursos Naturais Renováveis (IBAMA). Ainda deve ser citado o Instituto Chico Mendes de Conservação da Biodiversidade (ICMBio) que foi criado com a função de tutelar as Unidades de Conservação federais. A atual estrutura federal completa do SISNAMA é apresentada na figura 1:

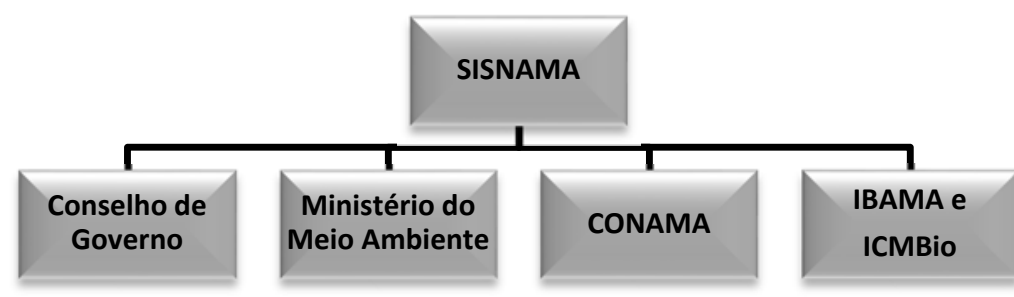

Figura 1: SISNAMA em âmbito federal, de acordo com o artigo $3^{\circ}$, do Decreto 99.274/1990.

Fonte: COSTA, S. L., baseado no Decreto 99.274/1990.

O Conselho de Governo e o Ministério do Meio Ambiente estão diretamente ligados à Presidência da República. O CONAMA é um órgão colegiado e tem como principal função a edição de resoluções sobre padrões de qualidade ambiental e outras normas ambientais (função deliberativa). São mais de 450 resoluções publicadas desde 1984, o que denota sua relevância para o sistema jurídico-ambiental brasileiro. Essa competência normativa do CONAMA não é incompatível com a competência dos demais entes federativos para legislar sobre meio ambiente, observando-se somente os padrões máximos de poluição tolerada estabelecidos pelo órgão deliberativo federal (ANTUNES, 2004, p.100).

O IBAMA, por sua vez, como órgão executor, tem as importantes funções de fiscalização, licenciamento e monitoramento ambientais. A fiscalização consiste em atuação preventiva e repressiva para inibição de infrações ambientais na esfera administrativa. O licenciamento ambiental é necessário para todas as atividades, obras ou serviços efetiva ou potencialmente poluidores, exatamente como forma de evitar ou minimizar estes impactos, estabelecendo condicionantes que devem ser monitoradas pelo respectivo órgão licenciador. Ainda deve ser 
referido o ICMBio que atua nas unidades de conservação federais, dentro do Sistema Nacional de Unidades de Conservação (SNUC).

No Âmbito Estadual do SISNAMA devem também existir, dentro da simetria com o modelo federal, órgãos centrais, consultivos/deliberativos e executores (órgãos seccionais). Nesse sentido, o Estado de Sergipe tem: a Secretaria de Estado do Meio Ambiente e dos Recursos Hídricos (SEMARH) (órgão central); o Conselho Estadual do Meio Ambiente (CEMA) (órgão consultivo/deliberativo) e a Administração Estadual do Meio Ambiente (ADEMA) (órgão executor). De acordo com a Lei da Política Estadual de Meio Ambiente de Sergipe (Lei 5.858/2006) estes órgãos integram o Sistema Estadual do Meio Ambiente (SISEMA) (art. 20).

Por sua vez, os municípios também têm a obrigação de se estruturar para integrar o SISNAMA (órgãos locais), com o objetivo de proteger o meio ambiente, no entanto, infelizmente, transcorridos mais de trinta anos da edição da Lei da Política Nacional do Meio Ambiente (LPNMA), muitos dos municípios brasileiros ainda estão inertes nesse sentido.

Em Sergipe, por exemplo, atualmente, nenhum município efetivamente integra o SISNAMA, embora um ou outro esteja em processo de integração, não havendo, entretanto, estrutura adequada para execução de suas competências ambientais. Existem municípios, como é o caso de Aracaju, que nem Secretaria do Meio Ambiente possuem (é o único município da região metropolitana nesta situação). Obviamente, isto não significa que o município não tem responsabilidade pela proteção ao meio ambiente (embora alguns administradores assim acreditem), pois a Constituição Federal estabelece em seu artigo 23 a responsabilidade de todos os entes federativos para tal proteção (SILVA, 2009, p.79), não podendo ser os municípios premiados por sua omissão, com a isenção de uma responsabilidade prevista pela própria Constituição Federal.

Entretanto, uma das consequências práticas dessa omissão municipal é que, não integrando o SISNAMA, não há como o município efetivar licenciamento ambiental. Destarte, atividades de impacto potencial local, que deveriam, como regra, ser licenciadas ambientalmente pelos próprios municípios como panificações, casas de shows, abatedouros, postos de gasolina, etc, passam a ter que ser licenciadas pelo órgão supletivo estadual (que, no caso de Sergipe, é a ADEMA), sobrecarregando-o e tornando ineficiente a rede pública integrada pelo SISNAMA de proteção do meio ambiente, já que os mais de 5565 municípios brasileiros são os entes federativos mais próximos da origem dos problemas ambientais relacionados à degradação antrópica.

Outra consequência é que não podem ser lavrados os autos de infração nos moldes da Lei 9.605/1998 e seu decreto regulamentador (Decreto 6.514/2008) que preveem multas de até cinquenta milhões de reais (art. 75, da Lei 9.605/1998), além de outras sanções administrativas (art. 72, da Lei 9.605/1998). Isto porque somente os agentes de fiscalização dos órgãos integrantes do SISNAMA e da Capitania dos Portos podem aplicar as multas previstas na Lei 9.605/1998 e seu Decreto 6.514/2008 (art. $70, \S 1^{\circ}$, da Lei $9.605 / 1998$ ). Tais multas, se aplicadas 
pelos municípios, poderiam ser revertidas para fundos municipais de meio ambiente, sendo assim aplicadas localmente para melhoria da qualidade ambiental (art. 73, da Lei 9.605/1998).

Não bastasse a omissão dos municípios na integração do SISNAMA, ainda deve ser questionada a ausência de recursos materiais e humanos adequados dos órgãos executores federais (ANTUNES, 2004, p. 98) e estaduais do SISNAMA que acabam se limitando à atividade licenciatória quando muito, não tendo estrutura para fiscalização e monitoramento (dos licenciamentos deferidos) adequados que garantam uma atuação preventiva de proteção do meio ambiente. Em Sergipe, por exemplo, a ADEMA, desde que foi criada em 1978, nunca fez um concurso público. Estes problemas estruturais da ADEMA estão sendo questionados atualmente pelo Ministério Público Estadual de Sergipe que ajuizou ação civil pública (201183001083) em face do Estado e da ADEMA para compeli-los judicialmente à realização do concurso público para seu quadro técnico.

\section{Licenciamento Ambiental e EIA/RIMA}

A LPNMA define ainda os conceitos jurídico-ambientais de degradação, poluição e licenciamento ambientais. A degradação ambiental seria a deterioração da qualidade do meio ambiente (também chamado de impacto ambiental negativo) e a poluição seria a degradação praticada pelo ser humano, pessoa física ou jurídica, sendo ainda objetiva a responsabilidade pelo dano ambiental (arts. $3^{\circ}$ e $14, \S 1^{\circ}$, da LPNMA). O licenciamento ambiental, de acordo com a LPNMA, seu Decreto Regulamentador em vigor (Decreto 99.274/1990), a LC 140/2011 e a Resolução CONAMA 237/1997 é o procedimento administrativo exigido para empreendimentos ou atividades potencialmente ou concretamente poluentes, onde, mediante estudos ambientais e condicionantes na licença ambiental expedida, busca-se o controle preventivo pelo poder público para a tutela do meio ambiente. Este controle é efetivado pelos órgãos executores do SISNAMA e a competência desta atuação é hoje definida pela Lei Complementar 140/2011, permanecendo a Resolução 237/1997 vigente nos demais aspectos.

O termo "licença" ambiental nem sempre guarda relação com o conceito do Direito Administrativo de licença (ato unilateral, vinculado e definitivo), havendo controvérsia sobre sua natureza na Doutrina. Nesse sentido: Trennepohl et al. (2008, p.26) leciona que a licença ambiental, na maior parte das vezes, teria natureza de autorização administrativa. Para Figueiredo (2008, p.183), a licença ambiental tem certo grau de discricionariedade e gera uma relação jurídica rebus sic standibus (p. 183). Para Antunes (2004, p.138) a licença ambiental não se confunde com a licença ou autorização do Direito Administrativo, pois no primeiro caso não há definitividade (deve ser renovada periodicamente) e, no segundo, porque não pode ser totalmente precária, tendo-se em vista os investimentos econômicos para implantação de empreendimentos. Fiorillo (2003, p.66), aduz ainda que a licença ambiental seria um ato discricionário sui generis. 
As licenças ambientais devem ser renovadas periodicamente, com o fito de manutenção de controle contínuo do poder público da harmonia entre a atividade licenciada e o meio ambiente. O licenciamento ambiental ordinário é dividido em três etapas inter-relacionadas que são apresentadas no quadro 1.

Quadro 1: Fases do licenciamento ambiental ordinário.

\begin{tabular}{|l|l|}
\hline Etapa & Função do órgão ambiental licenciador \\
\hline Licença prévia (LP) & $\begin{array}{l}\text { Verificar se o empreendimento proposto pode ser implantado na } \\
\text { localidade sem prejuízo do meio ambiente. }\end{array}$ \\
\hline Licença de instalação (LI) & $\begin{array}{l}\text { Analisar se o projeto do empreendimento é compatível com o local } \\
\text { aprovado, permitindo-se o início da implantação do empreendimento. }\end{array}$ \\
\hline Licença de operação (LO) & $\begin{array}{l}\text { Avaliar se o empreendimento foi instalado de acordo com a localização e } \\
\text { projetos aprovados na LP e LI, autorizando-se o início da atividade } \\
\text { licenciada. }\end{array}$ \\
\hline
\end{tabular}

Fonte: baseado no Decreto 99.274/1990.

É exatamente na fase preliminar do licenciamento ambiental, ou seja, na fase da licença prévia que o órgão ambiental integrante do SISNAMA exige do empreendedor estudos ambientais, definidos genericamente pela LPNMA como avaliação de impactos ambientais (AIA), às expensas deste, para subsidiar a decisão de concessão ou não de licença ambiental. $A$ publicidade do licenciamento abrange tanto o acesso público aos conteúdos dos estudos ambientais (resguardando-se pontos específicos sujeitos a sigilo industrial) diretamente no órgão ambiental (art. 17, $\S 3^{\circ}$, do Decreto 99.274/1990) ou ainda através de eventuais audiências públicas, com direito a participação no processo de licenciamento, como também na obrigatoriedade da publicação das licenças concedidas (art. 10, $1^{\circ}$, da LPNMA).

Entre os diversos estudos ambientais que podem ser exigidos pelo Órgão licenciador do SISNAMA, o estudo de impacto ambiental e seu respectivo relatório (EIA/RIMA) é um dos mais completos, complexos e, como não poderia deixar de ser, onerosos. Tal estudo foi regulamentado pelo CONAMA através da Resolução 01/1986, onde se definiu o conceito de impacto ambiental como:

Qualquer alteração das propriedades físicas, químicas e biológicas do meio ambiente, causada por qualquer forma de matéria ou energia resultante das atividades humanas que, direta ou indiretamente, afetam: I - a saúde, a segurança e o bem-estar da população; II - as atividades sociais e econômicas; III - a biota; IV - as condições estéticas e sanitárias do meio ambiente; $\mathrm{V}$ - a qualidade dos recursos ambientais. $\left(\right.$ art. $\left.1^{\circ}\right)$.

Além disso, a Resolução CONAMA 01/1986 apresenta rol exemplificativo de atividades que dependerão de EIA/RIMA (art. $2^{\circ}$ ) e os requisitos mínimos do estudo de impacto ambiental (arts. $5^{\circ}$ e $6^{\circ}$ ), os quais são apresentados no quadro 2 :

Quadro 2: Requisitos Mínimos do EIA.

Requisitos mínimos do ElA

I - Contemplar todas as alternativas tecnológicas e de localização do projeto, confrontando-as com a hipótese de não execução do projeto.

II - Identificar e avaliar sistematicamente os impactos ambientais gerados nas fases de implantação e operação da atividade.

III - Definir os limites da área geográfica a ser direta ou indiretamente afetada pelos impactos, denominada área de 
influência do projeto, considerando, em todos os casos, a bacia hidrográfica na qual se localiza.

IV - Considerar os planos e programas governamentais, propostos e em implantação na área de influência do projeto, e sua compatibilidade.

V - Apresentar Diagnóstico ambiental da área de influência do projeto completa descrição e análise dos recursos ambientais e suas interações, tal como existem, de modo a caracterizar a situação ambiental da área, antes da implantação do projeto.

VI - Analisar os impactos ambientais do projeto e de suas alternativas, através de identificação, previsão da magnitude e interpretação da importância dos prováveis impactos relevantes, discriminando: os impactos positivos e negativos

(benéficos e adversos), diretos e indiretos, imediatos e a médio e longo prazos, temporários e permanentes; seu grau de reversibilidade; suas propriedades cumulativas e sinérgicas; a distribuição dos ônus e benefícios sociais.

VII - Definição das medidas mitigadoras dos impactos negativos, entre elas os equipamentos de controle e sistemas de tratamento de despejos, avaliando a eficiência de cada uma delas.

VIII - Elaboração do programa de acompanhamento e monitoramento dos impactos positivos e negativos, indicando os fatores e parâmetros a serem considerados.

Fonte: Resolução CONAMA 01/1986.

O diagnóstico ambiental do EIA, indicado na Resolução CONAMA 01/1986, deve considerar no mínimo três dimensões: o meio físico - o subsolo, as águas, o ar e o clima, destacando os recursos minerais, a topografia, os tipos e aptidões do solo, os corpos d'água, o regime hidrológico, as correntes marinhas, as correntes atmosféricas; o meio biológico e os ecossistemas naturais - a fauna e a flora, destacando as espécies indicadoras da qualidade ambiental, de valor científico e econômico, raras e ameaçadas de extinção e as áreas de preservação permanente; o meio socioeconômico - o uso e ocupação do solo, os usos da água e a socioeconômica, destacando os sítios e monumentos arqueológicos, históricos e culturais da comunidade, as relações de dependência entre a sociedade local, os recursos ambientais e a potencial utilização futura desses recursos. (art. $6^{\circ}$ ). A Resolução CONAMA 01/1986, em seu artigo $9^{\circ}$, por sua vez, estabelece os requisitos mínimos do relatório de impacto ambiental, os quais são indicados no quadro 3 :

Quadro 3: Requisitos Mínimos do RIMA.

\begin{tabular}{|l|}
\hline Requisitos mínimos do RIMA \\
\hline I - Os objetivos e justificativas do projeto, sua relação e compatibilidade com as políticas setoriais, planos e programas \\
governamentais. \\
\hline II - A descrição do projeto e suas alternativas tecnológicas e locacionais, especificando para cada um deles, nas fases \\
de construção e operação a área de influência, as matérias primas, e mão-de-obra, as fontes de energia, os processos \\
e técnicas operacionais, os prováveis efluentes, emissões, resíduos e perdas de energia, os empregos diretos e \\
indiretos a serem gerados. \\
\hline III - A síntese dos resultados dos estudos de diagnósticos ambiental da área de influência do projeto. \\
\hline IV - A descrição dos prováveis impactos ambientais da implantação e operação da atividade, considerando o projeto, \\
suas alternativas, os horizontes de tempo de incidência dos impactos e indicando os métodos, técnicas e critérios \\
adotados para sua identificação, quantificação e interpretação. \\
\hline V - A caracterização da qualidade ambiental futura da área de influência, comparando as diferentes situaçães da \\
adoção do projeto e suas alternativas, bem como com a hipótese de sua não realização. \\
\hline VI - A descrição do efeito esperado das medidas mitigadoras previstas em relação aos impactos negativos, \\
mencionando aqueles que não puderem ser evitados, e o grau de alteraçãao esperado. \\
\hline VII - O programa de acompanhamento e monitoramento dos impactos. \\
\hline VIII - Recomendação quanto à alternativa mais favorável (conclusões e comentários de ordem geral). \\
\hline
\end{tabular}

Fonte: Resolução CONAMA 01/1986.

Como já observado, com o advento da Constituição Federal de 1988, o EIA/RIMA passou a ter status constitucional, sendo indispensável para empreendimentos que tivessem potencial de causar significativa degradação ambiental e enfatizando-se sua anterioridade à localização, instalação e operação do empreendimento, passando a ser denominado então estudo prévio de 
impacto ambiental, embora tenha se mantido o uso da sigla EIA na legislação e na literatura. Em 1990, o Decreto 99.274 ratificou, em seu artigo $17, \S 1^{\circ}$, os requisitos gerais do EIA/RIMA.

Vale frisar ainda que além dos casos previstos normativamente, caberá ao órgão ambiental competente para o licenciamento definir o risco de degradação ambiental pela localização (LP); instalação, construção, ampliação ou modificação (LI); operação (LO) de um dado empreendimento, justificando-se assim a necessidade do licenciamento ambiental e, em casos de possibilidade de significativa degradação ambiental, do próprio EIA/RIMA. A Resolução 237/1997, em seu artigo 10, aponta roteiro do procedimento de licenciamento ambiental, aqui apresentado no quadro 4:

Quadro 4: Fases administrativas do licenciamento ambiental.

Roteiro do Licenciamento Ambiental

I - Definição pelo órgão ambiental competente, com a participação do empreendedor, dos documentos, projetos e estudos ambientais, necessários ao início do processo de licenciamento correspondente à licença a ser requerida.

Certidão de uso e ocupação do solo emitida pelo município onde se se pretende localizar o empreendimento é obrigatória.

II - Requerimento da licença ambiental pelo empreendedor, acompanhado dos documentos, projetos e estudos ambientais pertinentes, dando-se a devida publicidade.

III - Análise pelo órgão ambiental competente, integrante do SISNAMA, dos documentos, projetos e estudos ambientais apresentados e a realização de vistorias técnicas, quando necessárias.

IV - Solicitação de esclarecimentos e complementações pelo órgão ambiental competente integrante do SISNAMA, uma única vez, em decorrência da análise dos documentos, projetos e estudos ambientais apresentados, quando couber, podendo haver a reiteração da mesma solicitação caso os esclarecimentos e complementações não tenham sido satisfatórios.

V - Audiência pública, quando couber, de acordo com a regulamentação pertinente (Res. CONAMA 09/1997).

VI - Solicitação de esclarecimentos e complementações pelo órgão ambiental competente, decorrentes de audiências

públicas, quando couber, podendo haver reiteração da solicitação quando os esclarecimentos e complementações não tenham sido satisfatórios.

VII - Emissão de parecer técnico conclusivo e, quando couber, parecer jurídico.

VIII - Deferimento ou indeferimento do pedido de licença, dando-se a devida publicidade.

Fonte: Resolução CONAMA 237/1997.

O exercício de atividade dependente de licenciamento ambiental sem a respectiva licença, com esta vencida ou ainda com inobservância das condicionantes estabelecidas pode constituirse em ilícitos administrativo, cível e penal no Brasil. llícito administrativo previsto no artigo 66, do Decreto 6.514/2008, com previsão de pena de multa de até dez milhões de reais; ilícito civil, com a reparação do dano patrimonial e moral ao meio ambiente e ilícito penal, com previsão de pena privativa de liberdade de um a seis meses de detenção ou/e multa (artigo 60, da Lei 9.605/1998). Deve ser ressaltada a previsão da possibilidade de cumulação das sanções administrativa, civil e penal, isto sem prejuízo da responsabilização penal da pessoa jurídica (art. $225, \S 3^{\circ}$, da CF c/c art. $3^{\circ}$, da Lei $\left.9.605 / 1998\right)$.

\section{Licenciamento Ambiental no Brasil depois da LC 140/2011}

O licenciamento ambiental brasileiro, fundamentado na Lei da Política Nacional do Meio Ambiente, tinha a Resolução CONAMA 237/1997 como principal norma delimitadora das atribuições dos entes federativos (União, Estados, Distrito Federal e Municípios) dentro do 
Sistema Nacional do Meio Ambiente (SISNAMA). A Lei Complementar 140, de 08/12/2011, passou a regular tais atribuições:

Esta Lei Complementar fixa normas, nos termos dos incisos III, VI e VII do caput e do parágrafo único do art. 23 da Constituição Federal, para a cooperação entre a União, os Estados, o Distrito Federal e os Municípios nas ações administrativas decorrentes do exercício da competência comum relativas à proteção das paisagens naturais notáveis, à proteção do meio ambiente, ao combate à poluição em qualquer de suas formas e à preservação das florestas, da fauna e da flora. (art. $1^{\circ}$, da LC 140/2011).

Sob pena de se violar a autonomia dos entes federativos, somente a Constituição Federal pode estabelecer as atribuições de cada um e indicar como estas serão delimitadas. De acordo com o artigo 225, da Constituição Federal, a atuação do poder público é fundamental para a preservação e defesa do meio ambiente ecologicamente equilibrado para estas e futuras gerações. Em seu artigo 23, foi estabelecida a competência comum dos entes federativos, onde a proteção do meio ambiente, em todas suas dimensões ganha destaque (art. 23, III, IV, VI, VII, IX, etc.) e ficou claro que tanto a União como os Estados, o Distrito Federal e os Municípios têm o dever de proteger o meio ambiente.

Para Antunes, a competência comum é "uma imposição constitucional para que os diversos integrantes da Federação atuem em cooperação administrativa recíproca, visando resguardar os bens ambientais" (2004, p. 88). Nessa tarefa do poder público de proteger o meio ambiente, o licenciamento ambiental é indispensável para empreendimentos ou atividades potencialmente ou efetivamente poluentes e caracterizado pelo controle prévio do poder público para se evitar a poluição.

Antes da regulamentação efetivada por meio da Resolução 237/1997, especificamente em relação ao licenciamento ambiental, surgiram problemas para se definir em que instância federativa deveria ser este efetivado, ao ponto de serem exigidos, em algumas oportunidades, licenciamentos simultâneos nas esferas municipal, estadual e federal, gerando-se insegurança jurídica e ônus desnecessários para os empreendedores. Para tentar acabar com esta polêmica e, principalmente, instituir o sistema de licenciamento ambiental único, o Conselho Nacional do Meio Ambiente (CONAMA) instituiu a Resolução 237/1997 estabelecendo, entre outras questões, como se daria esta distribuição de atribuições comuns aos entes federativos.

Entretanto, de acordo com a Constituição Federal (art. 23, parágrafo único), caberia à Lei Complementar tal função, razão pela qual, com razão, a doutrina apontava a inconstitucionalidade de tal resolução. Com o advento da Lei Complementar 140/2011, estas competências administrativas (ou materiais ou executivas) comuns dos entes federativos relativas à proteção ao meio ambiente, agora estão regulamentadas. No que tange ao licenciamento ambiental, verificase que as normas estabelecidas na Resolução 237/1997 foram ratificadas, sem grandes alterações, por tal Lei Complementar, permanecendo o sistema único de licenciamento pelos órgãos executores do Sistema Nacional de Meio Ambiente (art. 13), com a garantia de manifestação não vinculante dos órgãos ambientais das outras esferas federativas. 
A Lei Complementar 140/2011 ratificou o conceito de licenciamento ambiental já previsto na Lei da Política Nacional do Meio Ambiente e na Resolução CONAMA 237/97 como destinado à "[...] atividades ou empreendimentos utilizadores de recursos ambientais, efetiva ou potencialmente poluidores ou capazes, sob qualquer forma, de causar degradação ambiental" (art. $\left.2^{\circ}, I\right)$. No que tange à atribuição para licenciamento ambiental dos entes federativos verifica-se que, como regra, foi mantido o critério da abrangência do impacto: se local, cabe aos municípios; se extrapola mais de um município dentro de um mesmo estado, cabe a este o licenciamento e se ultrapassa as fronteiras do estado ou do país cabe ao órgão federal específico.

Além disso, cabe à União o licenciamento ambiental de empreendimentos e atividades: localizados ou desenvolvidos no mar territorial, na plataforma continental ou na zona econômica exclusiva (critério geográfico); localizados ou desenvolvidos em terras indígenas (critério do interesse nacional); localizados ou desenvolvidos em unidades de conservação instituídas pela União, exceto em Áreas de Proteção Ambiental (APAs) (critério da dominialidade); de caráter militar, excetuando-se do licenciamento ambiental, nos termos de ato do Poder Executivo, aqueles previstos no preparo e emprego das Forças Armadas (critério da segurança nacional); relativos à energia nuclear ou materiais radioativos (critério da segurança nacional); que atendam tipologia estabelecida por ato do Poder Executivo, a partir de proposição da Comissão Tripartite Nacional ("formada, paritariamente, por representantes dos Poderes Executivos da União, dos Estados, do Distrito Federal e dos Municípios, com o objetivo de fomentar a gestão ambiental compartilhada e descentralizada entre os entes federativos"). (art. $7^{\circ}$, XIV).

No caso de empreendimentos situadas na zona costeira com localização na faixa terrestre e marítima o licenciamento somente será federal (por esta circunstância apenas) nos casos indicados expressamente pelo executivo, a partir de proposta de tipologia da Comissão Tripartite Nacional (art. $7^{\circ}$, parágrafo único, da LC 140/2011). É importante ressaltar que, em todas as situações de licenciamento federal, caberá ao IBAMA tal atividade, condicionando-se, em alguns casos, à autorização ou parecer de outros órgãos mais específicos, tais como casos de empreendimentos localizados ou desenvolvidos em unidades de conservação federal, onde há participação obrigatória do ICMBio e também relacionados à energia nuclear ou a materiais radioativos, sujeitos à parecer da Comissão Nacional de Energia Nuclear - CNEN (art. $7^{\circ}, \mathrm{XV}$, "g", da LC 140/2011).

Para os Estados foi adotado o critério da competência licenciatória residual (pode licenciar aquilo que não for da atribuição da União e dos Municípios, o que redunda no critério da abrangência do impacto), sendo-Ihe expressamente estabelecida, assim como para os municípios, a atribuição para licenciamento de atividades ou empreendimentos em unidades de conservação estaduais ou municipais respectivamente, com exceção de área de proteção ambiental (APA). (arts. $8^{\circ}$, XIV e XV e $9^{\circ}$, XIV, "b"). O quadro 5 mostra a síntese da definição de competências da LC 140/2011: 
Quadro 5: Distribuição de competências para o licenciamento ambiental da LC 140/2011.

\begin{tabular}{|l|l|}
\hline $\begin{array}{l}\text { Ente } \\
\text { Federativo }\end{array}$ & Competência para o licenciamento ambiental, de acordo com o empreendimento \\
\hline \multirow{4}{*}{ Município } & Com possíveis impactos locais. \\
\cline { 2 - 2 } & Localizados em unidades de conservação municipais. \\
\hline \multirow{5}{*}{ União } & Com possíveis impactos estaduais. \\
\cline { 2 - 2 } & Localizados ou desenvolvidos em unidades de conservação estaduais. \\
\cline { 2 - 2 } & Lom impactos interestaduais (regionais), nacionais ou internacionais. \\
\cline { 2 - 2 } & $\begin{array}{l}\text { Localizados ou desenvolvidos em unidades de conservação federais. } \\
\text { exclusiva. }\end{array}$ \\
\cline { 2 - 2 } & De caráter militar. \\
\cline { 2 - 2 } & $\begin{array}{l}\text { Que atendam tipologia estabelecida por ato do Poder Executivo, a partir de proposição da Comissão } \\
\text { Tripartite Nacional. }\end{array}$ \\
\cline { 2 - 2 } & Relativos à energia nuclear ou a materiais radioativos. \\
\hline
\end{tabular}

Fonte: Bbaseado na LC 140/2011.

Em caso de conflitos de competências para o licenciamento ambiental entre entes federativos de diversos níveis em casos concretos (o que implica também em conflitos de critérios) Trennepohl et al. (2008, p.29) indica a utilização de um critério mais abrangente - o da prevalência do interesse, o qual, entendemos que somente deve ser aplicado subsidiariamente. Como exemplo do uso do critério da prevalência do interesse pode ser citado o caso de um empreendimento desenvolvido em mais de duas unidades de conservação, onde existem UCs federais e municipais, prevalecendo neste caso o interesse da união.

Como se observou, definiu-se, como regra, que cada ente federativo é responsável pelo licenciamento ambiental de empreendimentos implantados em unidades de conservação criadas por estes entes. Em áreas de proteção ambiental, espécie de unidade de conservação de uso sustentável prevista na Lei 9.985/2000, desde que não caracterizada na situação concreta outra exceção (v.g., localizadas em dois ou mais estados), deverá ser aplicada a regra, ou seja, deverá ser verificada a abrangência do impacto do empreendimento, serviço ou atividade a ser licenciado.

Foi concretizada na LC 140/2011 a preocupação com os constantes atrasos dos órgãos ambientais nos procedimentos de licenciamento ambiental atualmente efetivados (art. 14) e com a proporcionalidade que deve ser verificada entre as taxas para o licenciamento ambiental, especificadas por estes órgãos, e o verdadeiro custo e complexidade do serviço prestado pelo órgão licenciador (art. $13, \S 3^{\circ}$ ). Vale ressaltar que, com exceção dos artigos $4^{\circ}$ a $7^{\circ}$, da Resolução CONAMA 237/1997 (normas de competência), esta continua regulamentando o licenciamento ambiental no Brasil nos demais aspectos, permanecendo em vigor naquilo que não contrariar LC $140 / 2011$.

A LC 140/2011 dispõe ainda que em caso de inexistência de órgão ambiental executor ou deliberativo ou ainda em caso de atraso injustificado no procedimento de licenciamento imputável ao órgão ambiental licenciador, outro ente federativo de maior abrangência atuará em caráter supletivo, através de seu respectivo órgão licenciador ou normativo (arts. $14, \S 3^{\circ}$ e 15 ). Foi estabelecida ainda a figura da atuação subsidiária, consistente na "ação do ente da Federação que visa a auxiliar no desempenho das atribuições decorrentes das competências comuns, quando solicitado pelo ente federativo originariamente detentor das atribuições [licenciatórias]" e 
que se dará, entre outras formas, através de apoio técnico, científico, administrativo ou financeiro (art. $2^{\circ}$, III c/c art. 16).

A Lei Complementar referida estabelece também, em polêmico dispositivo, a competência fiscalizatória dos entes federativos, permanecendo a atribuição comum de todos estes entes para a fiscalização e adoção de medidas urgentes para se evitar o dano ambiental, embora a atribuição para lavrar auto de infração e procedimento administrativo seja do órgão licenciador competente. (art. 17, caput, $\S \S 2^{\circ}$ e $3^{\circ}$ ). É importante destacar que foi ajuizada uma ação direta de inconstitucionalidade (ADI 4.757) contra a LC 140/2011, em abril de 2012, no Supremo Tribunal Federal (STF) pela Associação Nacional dos Servidores da Carreira de Especialista em Meio Ambiente e PECMA do IBAMA (ASIBAMA Nacional). Tal ADI questiona vícios materiais, por violação dos artigos 225 e 23 da CF, caracterizados, em suma, pela definição das atribuições de licenciamento e de fiscalização específicas dos entes federativos, esvaziando as atribuições da União e vícios formais, referente ao fato de o projeto ter sofrido alterações em sua redação no Senado e não retornado à Câmara dos Deputados antes de ser encaminhado para a sanção presidencial.

Dentro das normas questionadas pela ASIBAMA (inconstitucionalidade material), destacam-se: artigo 17 , caput e seus parágrafos $2^{\circ}$ e $3^{\circ}$ : Alega a ASIBAMA que tais normas seriam inconstitucionais por prever que somente o órgão licenciador pode lavrar auto de infração e instaurar procedimento administrativo para apuração de infração ambiental, sendo que os parágrafos $2^{\circ}$ e $3^{\circ}$ não sanam a inconstitucionalidade do caput. Além disso, o referido parágrafo $3^{\circ}$ infringiria os princípios da eficiência, da segurança jurídica e da proibição do retrocesso ambiental por permitir procedimentos administrativos simultâneos e condicionais; artigos $7^{\circ}, \mathbf{X I I I ~ e ~ X I V ; ~} \mathbf{8}^{\circ}$, XIII e XIV; $9^{\circ}$, XIII e XIV; $4^{\circ}, \mathrm{V}$ e VI; 14, $3^{\circ}$; 15; 20; 21: Estas normas seriam inconstitucionais por especificar ou delegar competências comuns, e, ainda, por restringir a competência supletiva da União; artigo $14^{\circ}, \mathbf{4}^{\circ}$ : pela criação de autorização ambiental ficta; artigo $7^{\circ}$, XIV, "h" e seu parágrafo único: pela possibilidade da Comissão Tripartite Nacional gerar obrigações e deveres para os entes federativos através de suas proposições.

Tal ADI tem como relatora a Ministra Rosa Weber e já tem parecer da Advocacia Geral da União pelo não conhecimento e, no mérito, pela improcedência (entende que a LC 140/2011 é constitucional). A Procuradoria Geral da República (PGR), já apresentou parecer 7308-PGR-RG, de autoria da Vice-Procuradora-Geral da República Deborah Duprat, datado de julho de 2012, rechaçando os argumentos de inconstitucionalidade formal no processo legislativo da LC 140/2011, vez que no Senado não houve alteração substancial da redação da referida norma. No que tange aos argumentos de inconstitucionalidade material, o Ministério Público Federal rechaçou a maioria dos questionamentos apresentados, já que a delimitação de atribuições licenciatórias e fiscalizatórias de cada ente federativo é possível dentro da competência comum.

No entanto, entende o Ministério Público Federal, de forma indubitavelmente pertinente, que os princípios da subsidiariedade e da proibição da proteção deficiente, no que diz respeito à 
atividade fiscalizatória, devem abranger, dentro da interpretação conforme a Constituição, toda a LC 140/2011, e, especificamente, a cláusula final do seu artigo 17, §3 ("prevalecendo o auto de infração ambiental lavrado por órgão que detenha a atribuição de licenciamento ou autorização a que se refere o caput") no sentido de que não se afete a idoneidade para impedir ou evitar o dano ambiental. Segundo o MPF:

Ou seja, apenas prevalece o auto de infração lavrado pelo órgão que detenha a atribuição para o licenciamento ou autorização caso este tenha possibilidade real de impedir ou fazer cessar o dano. Pretende-se, com isso, evitar possível estratégia de desqualificação do auto de infração originariamente lavrado mediante outra autuação praticamente anódina para a finalidade da proteção ambiental. [...] De resto, como houve uma impugnação a todo o diploma, e a causa de pedir, em controle concentrado, é aberta, esse norte - princípios da subsidiariedade e da proibição de proteção deficiente - deve permear toda a LC 140 no que diz respeito à atividade de fiscalização. (MPF, 2012, p.11, grifo nosso).

Observa-se que o cerne da preocupação da ADI 4.757 é exatamente a descentralização operada pela LC 140/2011, que, ressalte-se, é fundamental para que a rede pública de proteção ambiental seja efetiva no Brasil, meta que, desde a criação do SISNAMA, ainda não foi alcançada. Nesse sentido, Antunes, antes da vigência da LC 140/2011, já observava que:

A possibilidade de exigência de um tríplice licenciamento implica que, em não raras oportunidades, a sobreposição e a contradição de normas gere um clima de insegurança, quanto ao licenciamento, e de instabilidade jurídica. Com efeito, a inexistência de um sistema claramente definido de competências é um dos mais graves problemas da legislação ambiental brasileira e de sua aplicação. (2004, p.142).

O MPF, no parecer acima referido da ADI 4.757 destaca ainda a importância da regulamentação das competências comuns dos entes federativos:

Enfim, a lei complementar prevista no parágrafo único do art. 23 é importante instrumento (i) no estabelecimento de balizas para o exercício de competências administrativas comuns; (ii) para conferir segurança jurídica e, ao mesmo tempo, permitir ao cidadão o controle dos serviços postos a sua disposição; e (iii) na otimização de recursos e eficiência na gestão pública. (MPF, 2012, p. 8).

Com a devida vênia, discordamos da crítica de Mukai (2012) à redação dos parágrafos $2^{\circ}$ e $3^{\circ}$, do artigo 17 , acima comentado. Para o referido autor, tal redação viola o sistema federativo porque "dispõe que qualquer órgão ambiental pode determinar medidas" ou efetivar fiscalização em caso de infrações ambientais. No sentido do posicionamento do MPF (2012), não observamos a inconstitucionalidade especificada, haja vista que se trata de competência administrativa comum estabelecida pelo artigo 23 da Constituição a todos os entes federativos. Além do mais, ameaças ou agravamento de danos ao meio ambiente em nosso país de dimensões continentais são prevenidos de forma mais eficiente com o aumento do espectro de entes ou órgãos que possam atuar em sua defesa, garantindo-se somente que a sanção será efetivada em uma única instância a fim de se evitar o bis in idem, previsão que já existia, para a multa, no artigo 76 da Lei 9.605/1998. 


\section{CONCLUSÕES}

Desde a obra Silent Spring em 1962 e a NEPA, em 1969, houve uma evolução muito grande no reconhecimento da responsabilidade do poder público para garantir o meio ambiente ecologicamente equilibrado para as presentes e futuras gerações. Tal evolução ocorreu também no Brasil, no entanto, transcorridos mais de trinta anos da vigência da Lei da Política Ambiental Brasileira, a rede de proteção do SISNAMA é incompleta e ineficiente.

A municipalização do licenciamento ambiental, importante instrumento de controle preventivo de atividades poluentes, ainda é incipiente no país. Os órgão ambientais estaduais e federais não contam com recursos humanos e materiais adequados para o exercício de tão importante mister. Coincidentemente, depois de 23 anos, foi regulamentado o parágrafo único, artigo 23 da Constituição Federal que estabelece as competências materiais ambientais da União, Estados, Distrito Federal e Municípios através da Lei Complementar 140/2011.

A LC 140/2011 busca implementar um sistema descentralizado de proteção do meio ambiente, estabelecendo, entre outras normas, as competências de licenciamento e fiscalização de cada ente federativo dentro da competência comum executiva definida pela Constituição Federal, consolidando entendimentos doutrinários e jurisprudenciais e firmando-se como um marco regulatório do licenciamento ambiental no Brasil, sem prejuízo de outras normas do sistema jurídico-ambiental brasileiro. No entanto, fruto de uma polêmica discussão, a LC 140/2011 deixa lacunas e dúvidas, o que é natural no sistema jurídico, que deverão ser integradas e interpretadas para que o sistema de controle ambiental através do licenciamento flua e o controle de atividades econômicas seja efetivo para a tutela do meio ambiente, garantindo-se assim, o nosso futuro comum.

\section{REFERÊNCIAS}

ANTUNES, P.. Direito Ambiental. 7 ed. Rio de Janeiro: Lumen Juris, 2004.

COMISSÃO MUNDIAL SOBRE MEIO AMBIENTE E DESENVOLVIMENTO (CMMAD). Nosso Futuro Comum. Rio de Janeiro: Editora da Fundação Getúlio Vargas, 1988.

COSTA, S. L.. Gestão Integrada de Resíduos Sólidos Urbanos: aspectos jurídicos e ambientais. Aracaju: Evocati, 2011.

COSTA, S. L.. Licenciamento ambiental no Brasil depois da LC 140/2011. Brasília: Dou, 19 jan. 2011.

FIGUEIREDO, L. V.. Curso de Direito Administrativo. 9 ed. São Paulo: Malheiros Editores, 2008.

FIORILLO, C. A. P.. Curso de Direito Ambiental Brasileiro. São Paulo: Saraiva, 2003.

MACHADO, P. A. L.. Direito Ambiental Brasileiro. 13 ed. São Paulo: Malheiros, 2005.

BRASIL. A Lei Complementar $n^{\circ} 140,08$ de dezembro de 2011. Dispõem sobre as diretrizes para a cooperação entre os entes federativos em matéria ambiental. Brasília, 08 de Dez 2011. 
RIOS, A. V. V.; ARAÚJO, U.. Política Nacional do Meio Ambiente. São Paulo: IEB - Instituto Internacional de Educação do Brasil, 2005.

SILVA, J. A..Direito Ambiental Constitucional. 7 ed. São Paulo: Malheiros, 2009.

TRENNEPOHL, C. et al. Licenciamento Ambiental. 2 ed. Niterói: Impetus, 2008. 